\title{
Towards sustainable irrigation in Western Australia
}

\author{
M. R. Rivers ${ }^{1}$, A. F. McCrea ${ }^{2}$, G. Calder ${ }^{3}$, K. Moore ${ }^{4}$, R. Kuzich ${ }^{5}$, \\ D. Hanks ${ }^{6} \&$ D. Nandapi ${ }^{7}$ \\ ${ }^{1}$ Department of Agriculture and Food, Western Australia, Waroona, \\ Western Australia \\ ${ }^{2}$ Department of Environment, East Perth, Western Australia \\ ${ }^{3}$ Harvey Water, Harvey, Western Australia \\ ${ }^{4}$ Boorara Research and Management, Leederville, Western Australia \\ ${ }^{5}$ Kuzich and Co., Manjimup, Western Australia \\ ${ }^{6}$ Taylynn Farms, Harvey, Western Australia \\ ${ }^{7}$ Smart Cow Consulting, Binningup, Western Australia
}

\begin{abstract}
This paper summarises the results and implications from two research trials, both undertaken in the Harvey Irrigation Area (HIA) in South Western Australia. The first trial assessed the sustainability of irrigation in the HIA at the regional, or irrigation scheme, scale. The second assessed a number of irrigation Best Management Practices (BMPs) at the farm-scale and then applied these results to their potential system-scale implications.

The single most important point in terms of the sustainability of irrigated farming in the south west of Western Australia is likely to be the real (or more importantly, perceived) issue of nutrient export to regional waterways.

Nutrient losses from irrigated agricultural land were found to be associated more with winter rain-driven processes than with irrigation activities. Also, significant water and nutrient savings were observed to have been made when switching from traditional surface (flood) irrigation systems to more efficient, centre pivot systems.

However, these trials have shown that there are important nutrient assimilation and loss processes confounding apparently simple trial results. This is an important issue in determining how to appropriately assess the "sustainability" of irrigation practices.

Keywords: sustainability, Best Management Practice, irrigation, water use efficiency, eutrophication, runoff, catchment.
\end{abstract}




\section{Introduction}

Although Australia is the world's driest inhabited continent, Australians are the highest water users per capita in the world with the agricultural sector (largely irrigation) accounting for about $70 \%$ of total water use (Commonwealth of Australia [1], Australian Bureau of Statistics [2]).

In total, the irrigation industry in Western Australia is the single largest water use group in the State accounting for about 36\% (940 Gigalitres / year) of all licensed surface water and groundwater allocation. The Australian average of about $70 \%$ of water resources diverted for irrigation indicates considerably greater production in the Eastern States of the country.

Despite the relatively small scale in Western Australia, irrigation is a high value industry. From a total area of about 83,000 hectares, or 3\% of the total WA land area, returns to WA are more than $\$ 650$ million dollars a year. This value per hectare equates to more than three times the national average (Australian Academy of Technical Sciences and Engineering [3]).

Licensed groundwater allocations for irrigation in WA total about 490 Gigalitres / year and are used to irrigate about 61,000 hectares (McCrea and Balakumar [4]). This represents approximately 55\% of the total water licensed for irrigation use. In comparison, about 450 Gigalitres / year are diverted from surface water resources and used to irrigate approximately 22,000 hectares. About $90 \%$ of the surface water used is supplied through four main irrigation schemes - the Ord, Carnarvon, Harvey, and Preston Valley schemes.

\subsection{Trial background}

The Harvey Irrigation Area (HIA) is Western Australia's prime irrigated dairying area supplying Perth and the south west of WA with more than 40 per cent of its milk. Irrigated agriculture commenced in Harvey with the establishment of a weir in 1916 and since that time pastures have been watered through surface irrigation of paddocks, which over time have been levelled and divided into individual irrigation bays.

The HIA currently has around 10,000 ha of land under permanent irrigation for dairy farming, beef grazing and horticulture, with a total irrigable area of approximately 30,000 ha. The region is presently experiencing some soil salinity problems common to other areas subject to irrigation, as well as producing nutrient-enriched drainage water that runs to environmentally sensitive estuarine receiving bodies including RAMSAR-listed wetlands, some of which have a long history of eutrophication and subsequent algal blooms.

\section{Regional surface water quality in the Harvey Irrigation Area: implications for regional environmental sustainability}

The need for an objective study examining the sustainability of irrigated agriculture in the HIA was identified by regional Natural Resource Management (NRM) partners as the quality of the water used for and following agricultural 
irrigation purposes in the area had not been well quantified. The popular view, however, in the broader community, and to some extent within the WA NRM community, appeared to be that irrigation farming in the region was a major contributor to surface water pollution lower in the catchment.

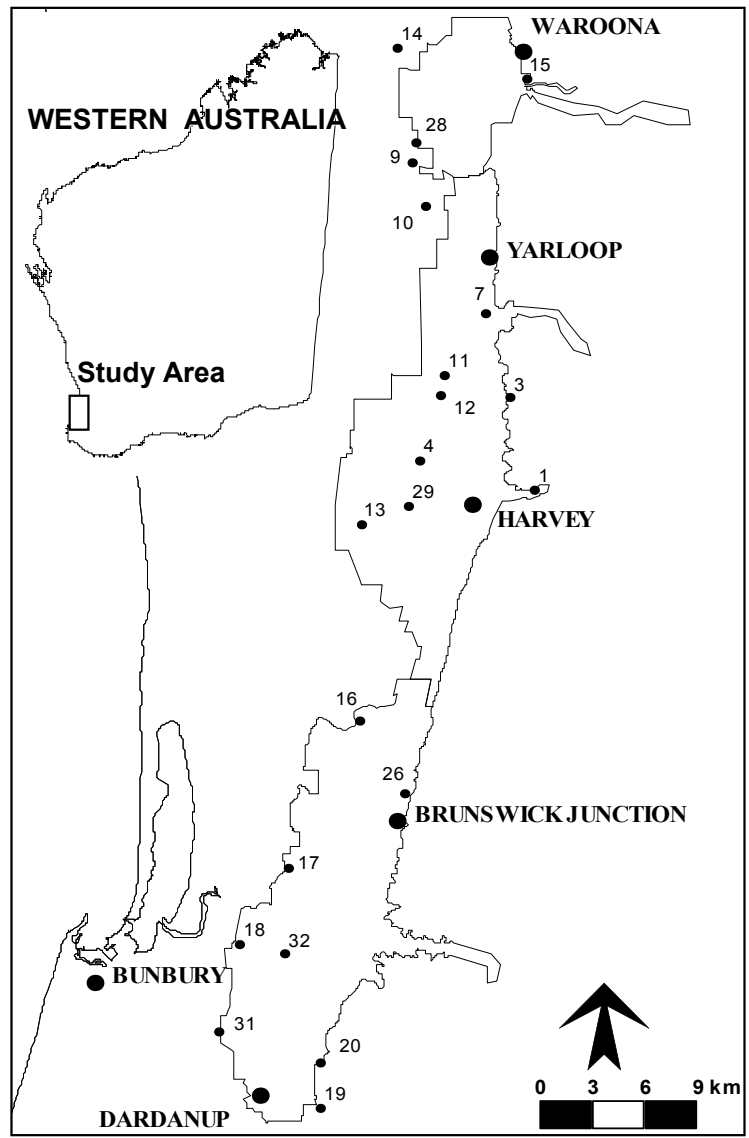

Figure 1: $\quad$ Location of sampling points within the Harvey Irrigation Area.

\subsection{Methods}

A suite of 21 monitoring sites was selected to reflect the quality of drainage water within the HIA and below the HIA in catchment terms. As well as being selected to provide an adequate coverage of channels and drains located higher and lower in the catchment, sites were selected to provide an adequate coverage of the three irrigation districts within the HIA - Waroona, Harvey and Collie - to determine if any district-specific differences could be observed. The location of these points can be seen in Figure 1.

Water samples were collected fortnightly during winter when irrigation water was not being released, and weekly during the summer months following the 
commencement of the irrigation season. Water samples were analysed in-situ or at the offices of the Department of Agriculture and Food for $\mathrm{pH}$, turbidity and EC using hand held metering systems, and were transported to Murdoch University for nutrient analysis.

\subsection{Discussion}

$\mathrm{pH}$ and turbidity levels monitored throughout the channel and drain points generally fell within the acceptable guidelines while exhibiting fluctuations which are commonly measured in water bodies of this type.

Two significant points were apparent from the EC data:

EC levels in water sourced from the Wellington Dam and distributed throughout the Collie irrigation district generally exceeded the MRL for irrigation supply water by more than $100 \%$. They also, generally, exceed the MRL for the protection of freshwater aquatic ecosystems. The average EC levels in this district increased annually for all three years of the monitoring programme.

\subsubsection{Summary of macro nutrient concentration variations and patterns}

Generally, nutrient concentrations in the waters of the distribution channels were below the maximum recommendations (ANZECC, [5]) while water within the drains was at about the ANZECC level most of the time, with short periods during which the ANZECC levels were exceeded.

Nitrogen concentrations in drainage water were found to be statistically higher during periods of dryland farming (outside of the irrigation periods) when compared with concentrations measured during irrigation periods. The median values during the dryland farming period were $1.4 \mathrm{mg} / \mathrm{L}$ compared with 0.95 $\mathrm{mg} / \mathrm{L}$ during irrigation. This means that, in terms of measured nutrient concentrations, water flowing during irrigation has nitrogen levels $32 \%$ lower than those measured during winter. Or, water measured in winter holds 1.5 times the nitrogen held during irrigation.

Phosphorus concentrations between periods of irrigation and non-irrigation were not statistically different.

Increased nutrient concentrations in winter may reflect a number of issues: the dominant influence of rainfall over irrigation on the transport of water-borne nutrients in the south west WA environment; the effectively larger available catchment for rainfall during winter compared with irrigation "catchments" during summer; the influence of winter waterlogging on the release of nutrients under anoxic soil conditions, and; the influence of bare or non-productive areas outside of irrigation bays (where nutrients are not being utilised by plant growth) on the overall water quality.

Further analyses have been undertaken which examine the nutrient loadings based on measured flow rates. On average, while $79 \%$ of water travels through the irrigation system during winter, this water carries $88 \%$ of the phosphorus and $86 \%$ of the nitrogen exported annually. Irrigation water, while accounting for $21 \%$ of the water measured during the monitoring programme, carried $12 \%$ of the total phosphorus measured and $14 \%$ of the nitrogen. 
Average nutrient loads per unit area are $6.0 \mathrm{~kg} / \mathrm{ha} / \mathrm{yr}$ (phosphorus) and 69.62 $\mathrm{kg} / \mathrm{ha} / \mathrm{yr}$ (nitrogen) during winter when the irrigation system is collecting dryland farming drainage water, and $0.89 \mathrm{~kg} / \mathrm{ha} / \mathrm{yr}$ (phosphorus) and $14.56 \mathrm{~kg} / \mathrm{ha} / \mathrm{yr}$ (nitrogen) during the summer irrigation period. The summer (irrigation) nutrient loads are observably lower than winter (non-irrigation) loads. This is especially significant as the irrigation season catchments are generally much smaller than the winter catchments. Given these variations in catchment size the larger (winter) catchments might in fact be expected to produce lower loads per unit area because of dilution factors.

However, when these figures are considered in comparison with other parts of the Swan Coastal Plain of similar size, it is clear that the irrigation area discharges significantly more nutrients than adjacent dryland farming areas of lighter, sandier soil. It appears, though, that the contribution to this from the irrigation season is relatively minor. For example, the total annual amount of phosphorus exported from the (estimated) 11,457 ha monitored as part of this programme is 58 tonnes. As a comparison, this equates to almost $40 \%$ of the total phosphorus export of the Peel-Harvey Catchment from only $6 \%$ of the area. This association has been made before (Birch, [6]). This study found that increasing phosphorus export rates within the Peel-Harvey catchment were closely associated with three factors: heavy soils, phosphorus application rates and dairying as a land use. It has also been noted (Attwater, [7]) that up to $80 \%$ of heavy soils within the southern portion of the Swan Coastal Plain already contain optimum or excess levels of phosphorus. Further phosphorus applied to these soils is generally lost to runoff and leaching.

Within the HIA, none of these factors can be viewed in isolation. The heavier soils have a naturally higher ability to retain phosphorus, and therefore require more phosphorus to provide plants with sufficient levels for growth. Also, the predominant dairying landuse exists within these regions, as they are the most productive.

High nutrient loads from the HIA are associated with the regional soils, predominant land use and associated high production levels, but are not due to irrigation per se.

\section{On-farm assessment of WA irrigation practices and proposed BMPs}

In addition to the system-scale assessment discussed above, work was also undertaken on an irrigated dairy located within the HIA and near the town of Harvey (see Figure 2).

Automatic water sampling equipment was installed to examine the amount of runoff and the quality of water leaving surface irrigation areas under different management regimes. It compared this with any losses from centre-pivot irrigated areas. Groundwater samples were also taken and any changes to groundwater levels or quality under the different systems recorded. Pasture quantity and quality was also measured by a consultant agronomist and soil moisture monitoring was used to manage the irrigation scheduling of the surface and centre pivot both systems. 


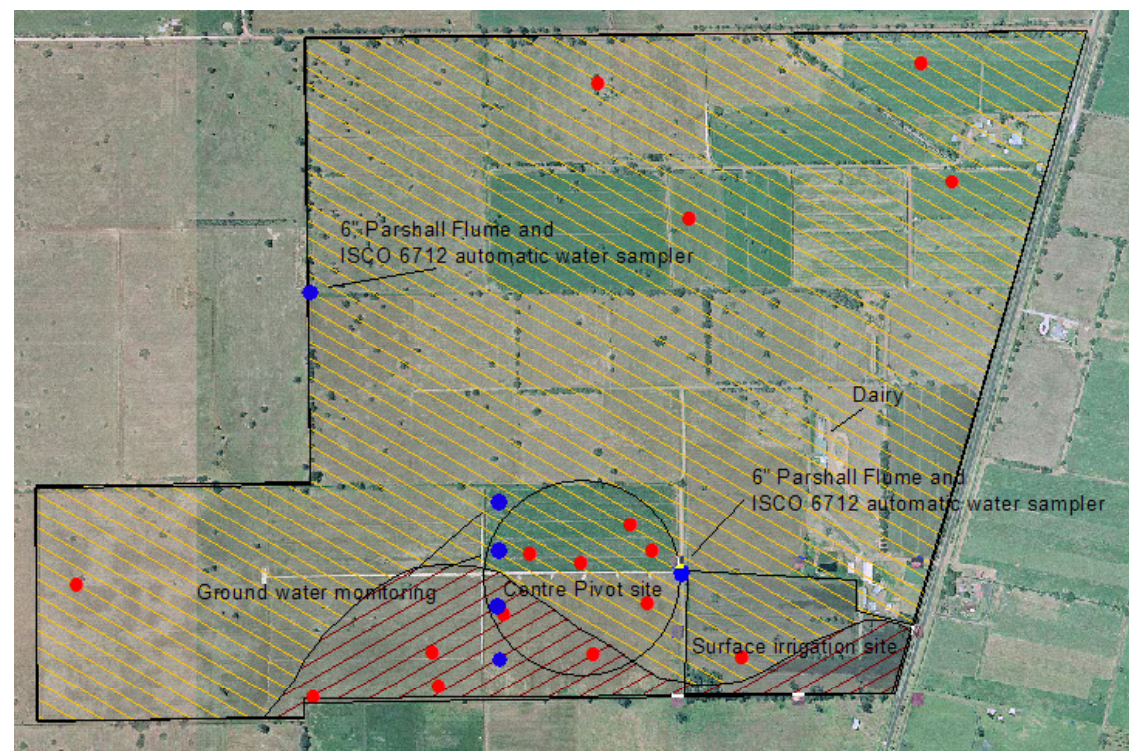

Figure 2: $\quad$ Layout of Harvey irrigation farm study area.

Table 1: $\quad$ Water use measures, irrigation seasons 2003-04 and 2004-05.

\begin{tabular}{|l|c|c|c|c|c|}
\hline & \multicolumn{2}{|l|}{ Surface } & \multicolumn{2}{l|}{ Centre Pivot } & \\
\hline & $\begin{array}{c}\text { Total } \\
(\mathrm{ML})\end{array}$ & per hectare & $\begin{array}{c}\text { Total } \\
(\mathrm{ML})\end{array}$ & $\begin{array}{c}\text { per } \\
\text { hectare }\end{array}$ & CP vs. Surface \\
\hline $2003 / 2004$ & 109 & 18 & 67 & 8 & $56 \%$ \\
\hline $2004 / 2005$ & 71 & 11 & 68 & 8 & $28 \%$ \\
\hline $03 / 04$ vs. 04/05 & & $39 \%$ & & 0 & \\
\hline
\end{tabular}

\subsection{Water use efficiency}

The results for the respective sites for the 2003-04 and 2004-05 irrigation seasons are shown in Table 1.

The results show the superior performance of the centre pivot in delivering the amount of water required for pasture production. With the centre pivot, $56 \%$ less water was applied in year 1 compared with the surface bay and $28 \%$ less in year 2. For the pivot itself, water use was essentially unchanged. For the surface bay, 39\% less water was applied in year 2 .

The centre pivot results can be largely attributed to improved scheduling and management that resulted from the increased experience and confidence of the land manager. In the case of the surface site, research staff attended the site for most of each irrigation event in the second season to open and close gates at optimum times. This allowed quicker movement of water across the bay, resulting in less water being applied in 2004-05 compared with 2003-04. 


\subsection{Groundwater quality}

Groundwater quality in terms of both nitrogen and phosphorus was not of concern and were within the recommended maximum levels.

\subsection{Water losses to runoff}

Losses to runoff from the surface irrigation site for the 2003/04 irrigation season were very high (approximately 65\%). These figures were reported for a six hectare, three bay, surface irrigation trial site, (see Figure 2).

Following a review of the monitoring design and protocols, an additional flow control structure and automatic water sampler were installed at the tail drain of the first, individual irrigation bay. This site is referred to as 'Bay 1'. The runoff figures for the 2004/05 irrigation season, expressed as a percentage of applied water are shown in Table 2 below.

Table 2: Runoff losses from individual and combined surface irrigation bays.

\begin{tabular}{|l|l|l|}
\cline { 2 - 3 } \multicolumn{1}{c|}{} & Average (\%) & Range (\%) \\
\hline Bay 1 & 12 & $7-19$ \\
\hline 3 combined bays & 20 & $7-35$ \\
\hline
\end{tabular}

These figures are significantly better than the $65 \%$ measured during the 2003/04 irrigation season for the 3 combined bays. However, this would be expected given the reduction in water use and the ability to better manage the surface irrigation at the site during this season as discussed earlier.

It is also interesting to note the reduction in 'efficiency' between the individual bay scale and the 3-bay scale. This illustrates the cumulative effect of runoff from a series of irrigation bays irrigated together, and is also likely to be due to the less timely closing of gates in bays 2 and 3 because of less intensive monitoring and management of these bays.

\subsection{Nutrient concentrations in runoff water}

Nutrient concentrations measured in water samples taken during the irrigation seasons followed relatively predictable patterns at various scales. Highest concentrations of nutrients were measured in water flowing overland during irrigation events and, within events, concentrations were highest at the bottom of the irrigation bays. This would be the point when the water has had the maximum exposure to available nutrients on the soil surface and in the shallow subsurface. Levels of up to $44 \mathrm{mg} / \mathrm{L}$ and $66 \mathrm{mg} / \mathrm{L}$ for phosphorus and nitrogen respectively were measured in irrigation water flowing over the soil surface. 
However, maximum concentrations of nutrients measured at the tail drain of Bay 1 had reduced to $6.4 \mathrm{mg} / \mathrm{L}$ and $23.4 \mathrm{mg} / \mathrm{L}$ for phosphorus and nitrogen respectively. Nutrient concentrations at this scale again followed predictable patterns with the maximum values occurring at the commencement of runoff flow through the drain.

Maximum nutrient concentrations in water samples from the automatic sampler collecting water from the three combined irrigation bays, however, had increased concentrations. This may again show the importance of good irrigation management discussed above in terms of water losses.

Figure 3 further develops this relationship between phosphorus concentration in water samples and catchment scale. This data shows the strong relationships between both total phosphorus and soluble phosphorus and catchment size $\left(\mathrm{R}^{2}\right.$ of 0.98 and 0.96 respectively).

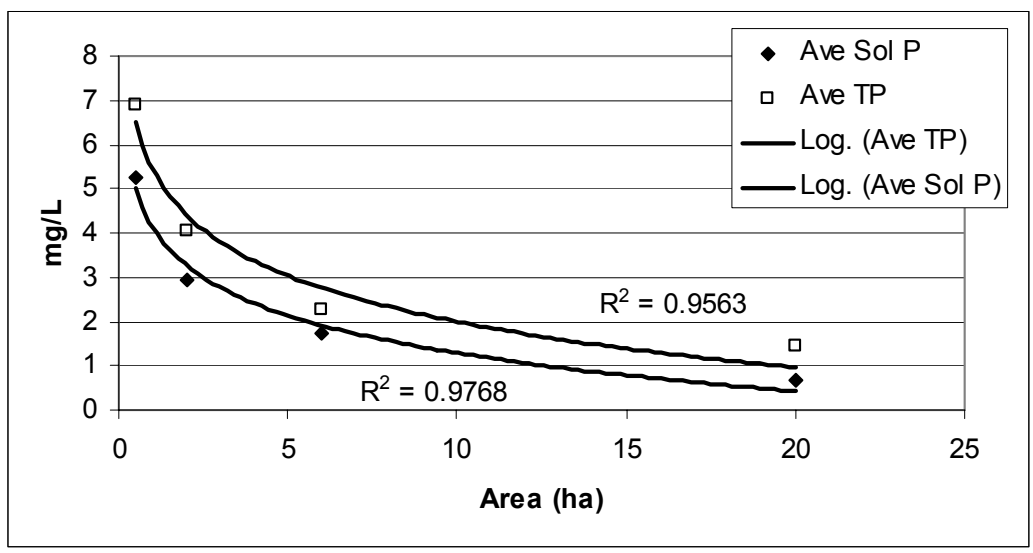

Figure 3: Phosphorus concentrations at increasing catchment areas.

This is a very important point, as the same land management practices are in place throughout the catchment scales from the irrigation bay scale to that of a large portion of the farm. It illustrates the fact that monitoring of land management practices at any scales larger than that at which the practices are implemented (in this case the scale of an irrigation bay) is unlikely to yield meaningful information because of the diluting influences of those parts of the catchment (farm) which do not contribute nutrients. It also illustrates the fact that phosphorus export reduction practices also need to be targetted at the appropriate, small scale at the nutrient source.

\subsection{Productivity}

Pasture productivity results demonstrate the outstanding potential of centre pivot irrigation to increase both the amount and quality of pasture needed for greater milk production as well as to reduce water and nutrient losses.

In $2003 / 04$, the centre pivot site produced $54 \%$ more pasture than the surface irrigated site (same management regime) and during 2004/05 it produced almost 
double the pasture. Pasture palatability was also better under the centre pivot system.

The estimated increase in milk production under the centre pivot system for $2003 / 04$ is 8,500 litres more milk per hectare than the surface irrigated site. This was achieved using far less water.

\section{Conclusion}

In summary, the following conclusions can be drawn from the research that was carried out across the farm and catchment-scale trials:

\subsection{Harvey Irrigation Area Project}

Problems with the high salinity levels of the water sourced from the Wellington Dam have been clearly shown. The exceedence of the recommended maximum limit for irrigation water for the entire irrigation season shows the limitations that this poor quality water will be inflicting on both regional agricultural productivity and regional, downstream water quality. This would have a marked effect on the real value of this irrigation water in terms of its ability to contribute to profitable and sustainable farming.

The nutrient concentrations in water collected during the irrigation season are similar to or lower than those collected in the same drains during winter. Irrigation nitrogen concentrations are of the order of $70 \%$ of those measured during winter.

Nutrient load calculations support the conclusions drawn from analyses of nutrient concentration data. That is, while $79 \%$ of water travels through the irrigation system during winter, this water carries $88 \%$ of the phosphorus and $86 \%$ of the nitrogen exported annually. Irrigation water, while accounting for $21 \%$ of the water measured during the monitoring programme, carried only $12 \%$ of the total phosphorus measured and $14 \%$ of the nitrogen.

However, the total nutrient export rates from the HIA are significantly higher than those from other regional catchments. This is likely to be associated with heavier soils in the irrigation districts, and more intensive farm practices

\subsection{Irrigation practice assessment}

Significant reductions in run-off loss from the surface irrigation site occurred in the second season due to closer management of this system. This has significant implications for automation of irrigation bay gates and suggests that this may be one of the more effective BMPs to pursue in this area. No runoff was observed at all from the centre pivot system.

Phosphorus concentrations are scale related; i.e., concentrations coming off individual bays are higher than combined bays for the same events. Phosphorus concentrations in tail drains and larger farm drains are similar to phosphorus concentrations in drains on non-irrigated properties.

Phosphorus concentrations at 'end of farm' monitoring points approached background levels, but were still above recommended maxima for ecosystem 
protection. Around $90 \%$ of phosphorus in run-off is the soluble and more ecologically active form.

The single most important point in terms of the sustainability of irrigated farming in the south west of Western Australia is likely to be the (perhaps perceived) issue of nutrient export to regional waterways. State regulators already have the ability to prosecute landowners for 'environmental harm' if those landowners cannot show that they are farming sustainably. It has been suggested that 'sustainability' may be measured in this context by the collection of water samples and their analysis for nutrient concentrations. The data presented here shows a very clear relationship between catchment size and nutrient concentration in runoff water.

\section{References}

[1] Commonwealth of Australia, Australian Water Resources Assessment 2000, Surface and groundwater-availability and quality, National Land and Water Resources Audit, National Heritage Trust, Canberra, June 2001.

[2] Australian Bureau of Statistics, Australia's Environment: issues and trends, ABS Catalogue no. 4613.0, Commonwealth of Australia, Canberra. 2003.

[3] Australian Academy of Technological Sciences and Engineering, Water and the Australian economy, Parkville, Victoria. 1999.

[4] McCrea A F and Balakumar B., Sustainability of irrigation in Western Australia, in Proc. XI World Water Congress water resources management in the $21^{\text {st }}$ century, International Water Resources Association, Madrid Spain, 5-9 October 2003.

[5] Australian and New Zealand Environment and Conservation Council (ANZECC). Australian Water Quality Guidelines for Fresh and Marine Waters. Canberra. 1992.

[6] Birch, P. B. Phosphorus export from coastal plain drainage into the PeelHarvey estuarine system of Western Australia. Australian Journal of Marine and Freshwater Research. 33. 1982.

[7] Attwater, R. C. The Peel-Harvey soil testing program, 1983-1990. Agriculture Western Australia. Perth. WA. 1997. 